\title{
Hydraulic Fracture Growth in Coal
}

\author{
R.G. Jeffrey CSIRO Petroleum, Australia
}

X. Zhang CSIRO Petroleum, Australia

\begin{abstract}
A significant number of hydraulic fracture treatments in coal seams have been mined and the propped fracture geometry mapped. Efforts to monitor fracture growth remotely or by measuring pressure in offset wells have added to the database on fracture growth in coal. Despite this considerable body of work, fracturing coal still can result in unexpected response and model predictions of fracture pressure and extent are unreliable, unless considerable empirical experience is available and used to calibrate the model for any new site. This state of affairs is a result of the layered and naturally fractured nature of coal. This paper will present selected data from lab and field experiments and modelling results that together provide an insight into the main factors contributing to high treating pressure and shorter than expected length development for hydraulic fracture treatments in coal.
\end{abstract}

\section{Introduction}

Hydraulic fracturing has been used since the 1970s for stimulation of coal seam methane wells (Elder, 1977) and, more recently (Kravits, 1993; Jeffrey and Boucher, 2004), to enhance gas drainage rates from horizontal in-seam drain holes in underground coal mines. Hydraulic fracture stimulation of coal seam methane wells has often presented a challenge to the industry. Problems such as high breakdown or high treating pressures and poorer than anticipated stimulation effectiveness have occurred since the first stimulations and similar problems recur from time to time today. Even today many, if not most, fracture stimulations are developed through a process of trial and error with new areas often requiring the build-up of experience before treatments can be routinely completed without difficulty. Fracture design models play a part in the trial and error process but, if used at all, are usually employed with strong user intervention to force the model to produce what are believed by the user to be reasonable results.

Coal seams are highly naturally fractured and exist as one unit of a layered lithology with strong contrasts in properties between the coal and bounding rock layers. Differences in mechanical properties often give rise to strong contrasts in layer-parallel stresses in the coal and rock. These factors, combined with the coals chemical activity, all contribute to the challenge of stimulating coal seam wells.

This paper first presents a summary of several factors that are important to consider in planning and carrying out hydraulic fracture stimulations in coal and then recent results are given that add to the overall understanding of the process of fracture growth in coal.

\section{Measuring fracture geometry and growth mechanisms}

Mapping of hydraulic fractures in coal during and after mining has been carried out in the United States of America and Australia. This type of data has been very valuable in revealing the propped fracture geometry and extent (Jeffrey and Settari, 1998; Diamond and Oyler, 1987; Steidl, 1991). Microseismic, tiltmeter, offset well pressure monitoring, fracture treatment pressure analysis, and downhole video surveying have been used to add to the understanding of fracture growth in coal.

\subsection{Mapped fractures after mining}

The fractures mapped after mining have ranged from more or less planar fractures, to T-shaped, offset, and branched fractures with two or more sub-parallel propped channels. Some fractures are completely contained to the seam while others grow into the roof or the floor rock. If anything, when physically mapped fractures are discussed, the more complex fracture geometries are highlighted, probably because these complex 
fractures are more strikingly different from what conventional fracture models assume. Figure 1 contains drawings of four mapped fractures that illustrate the range of complexity that has been found by mineback mapping (Jeffrey et al., 1995; 1998).

Figure 1(a) shows a plan view of a propped fracture geometry mapped in central Queensland in the German Creek seam. This fracture grew in the face cleat direction, parallel to the maximum horizontal stress in the coal. Two secondary vertical branches grew initially along the butt cleat from the wellbore. These secondary branches eventually died out. High treating pressure was experienced in placing this fracture with a treating pressure gradient of $0.045 \mathrm{MPa} / \mathrm{m}$ of depth $(0.025 \mathrm{MPa} / \mathrm{m}$ is sufficient to open a horizontal fracture). No significant horizontal fracture development was mapped and the vertical fracture grew into the roof rock.

All of the fractures shown in Figure 1 were formed by injecting borate crosslinked gel fluids. Figure 1(b) shows a fracture containing a vertical and horizontal branch, with the horizontal branch extending on only one side. The treating pressure gradient decreased throughout the treatment and was $0.036 \mathrm{MPa} / \mathrm{m}$ at shut-in, consistent with horizontal fracture growth (Jeffrey et al., 1994). Figure 1c shows a vertical fracture that grew through the seam and into the roof rock (Jeffrey et al., 1995). Downward growth was arrested at a thin clay layer at the coal-floor rock interface. The treating pressure gradient for this fracture was $0.028 \mathrm{MPa} / \mathrm{m}$ at shut-in. And, finally, in Figure 1(d) a complex vertical section through a fracture with two horizontal and two vertical branches is shown (Jeffrey et al., 1992). The treatment produced a T-shaped fracture consisting of a large horizontal fracture at the coal-roof rock interface with a vertical fracture extending along the face cleat direction underneath the horizontal fracture. The treating pressure decreased throughout the injection and the pressure at shut-in reached a treating pressure gradient of $0.025 \mathrm{MPa} / \mathrm{m}$, consistent with growth of a horizontal fracture.

The mineback data reveals the propped geometry of the fracture channels but does not contain detailed information about the sequence of events that formed the fractures. For example, two parallel propped fracture can be mapped by mining, but one of the two branches may have formed first, filled with proppant and stopped growing with the second branch then forming and bypassing the first. Fracture models are useful at this point to help understand the most likely sequence of events resulting in development of complex fracture geometries.

\subsection{Monitored fracture response}

Offset boreholes can have pressure monitoring sensors installed into them before a fracture treatment. The pressure data recorded provides a measure of the fracture arrival at the borehole and the pressure at that point in the fracture itself. Several full-size treatments monitored this way in Australia produced pressure responses at the piezometer monitoring wells consistent with growth of a horizontal fracture. Stress conditions were such that T-shaped fractures could have been produced. A small scale experimental fracture carried out at Dartbrook mine created a vertical fracture that grew close to a monitoring well. This data was analysed in detail and the growth data was matched by including pressure dependent leakoff in the model, which increased the seam permeability by a factor that varied with effective stress (Jeffrey and Settari, 1998).

\section{Fracture growth mechanics}

A number of factors can contribute to the fracture growth response when hydraulic fracture treatments are carried out in coal seams. The mechanisms described below are all known to occur during stimulation of coal seams, but their relative contribution to the overall observed pressure and growth behaviour is not clear.

\subsection{Multiple fractures}

Early mineback data demonstrated that the propped fractures created in coal contained sections that consisted of multiple parallel or sub-parallel branches. Fractures have also been mapped that grow in both the face and butt cleat directions as shown in Figure 1(a) and 1(d), for example. Such multiple or secondary branches tend to extend a short distance compared with the overall extent of the main propped fracture. Fractures with horizontal and vertical branches, such as T-shaped fractures, are the exception. In these cases, both the horizontal and vertical branches may extend over the full fracture size. Jeffrey et al. (1989) calculated the pressure and opening of two parallel fractures propagating side-by-side as a function of the fracture length to 
spacing ratio (Figure 2). The limiting values for small $\mathrm{S} / \mathrm{L}$ ratios can be found by doubling the opening compliance in the analytical KGD equations for fracture width and net pressure. When this is done, the pressure is found to increase by 1.68 ( or $2^{3 / 4}$ ) and the width to be reduced by 0.84 (or $2^{-1 / 4}$ ) times the corresponding values for large S/L values. Note that these factors are for two parallel fractures and the base value of 1.0 is for two fractures that are not interacting because they are spaced far apart. If the wide-spaced base value is taken as a single fracture accepting the entire injection rate (twice that of each single fracture), then the close spaced asymptotes are 1.4 (or $2^{1 / 2}$ ) for pressure and 0.71 (or $2^{-1 / 2}$ ) for width.

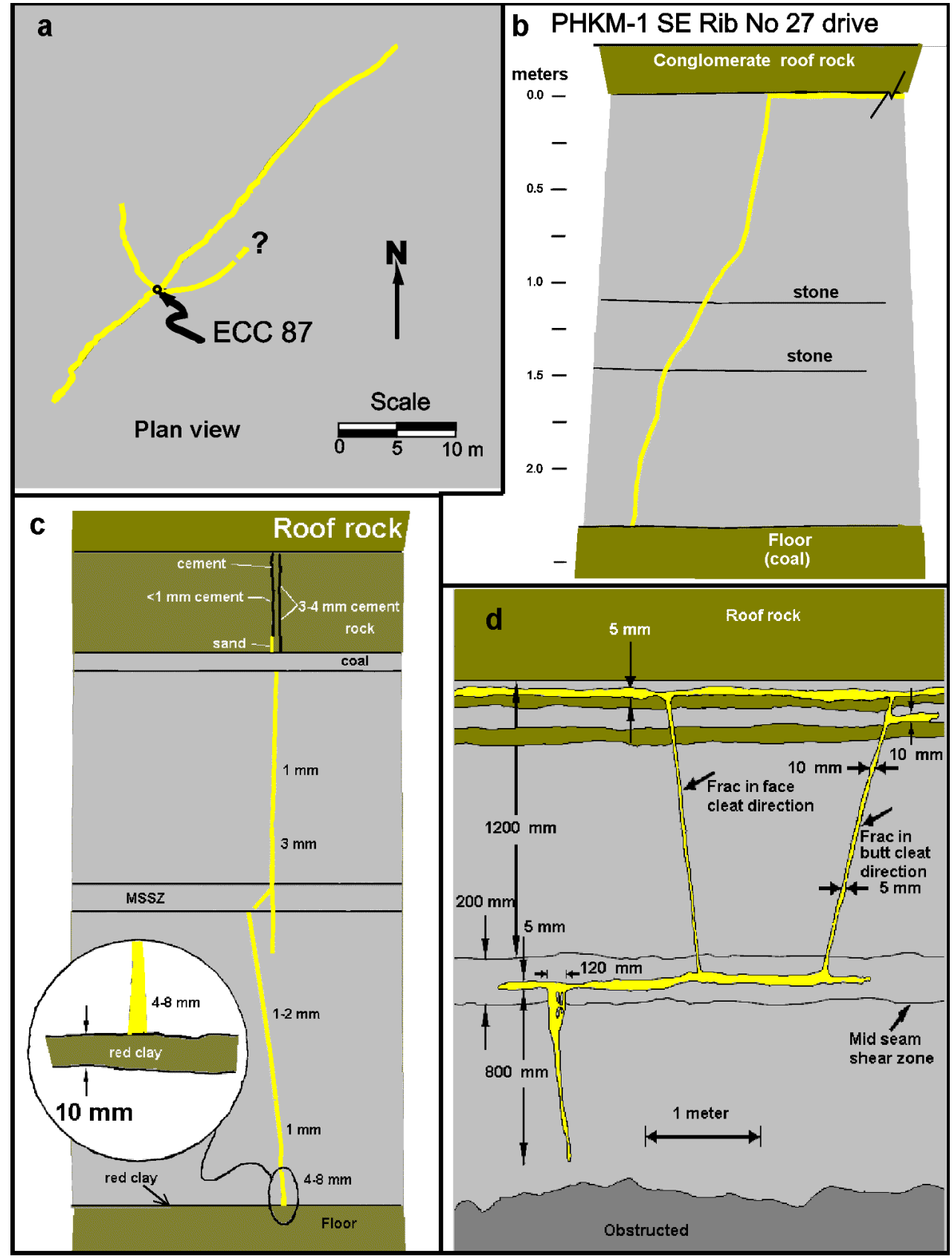

Figure 1 Several mapped hydraulic fractures in coal; a) Fracture with branches growing from wellbore; b) with a horizontal and vertical branch; c) vertical fracture growing into roof rock; d) complex fracture with multiple vertical and horizontal branches 


\section{Response of Two Parallel Fractures}

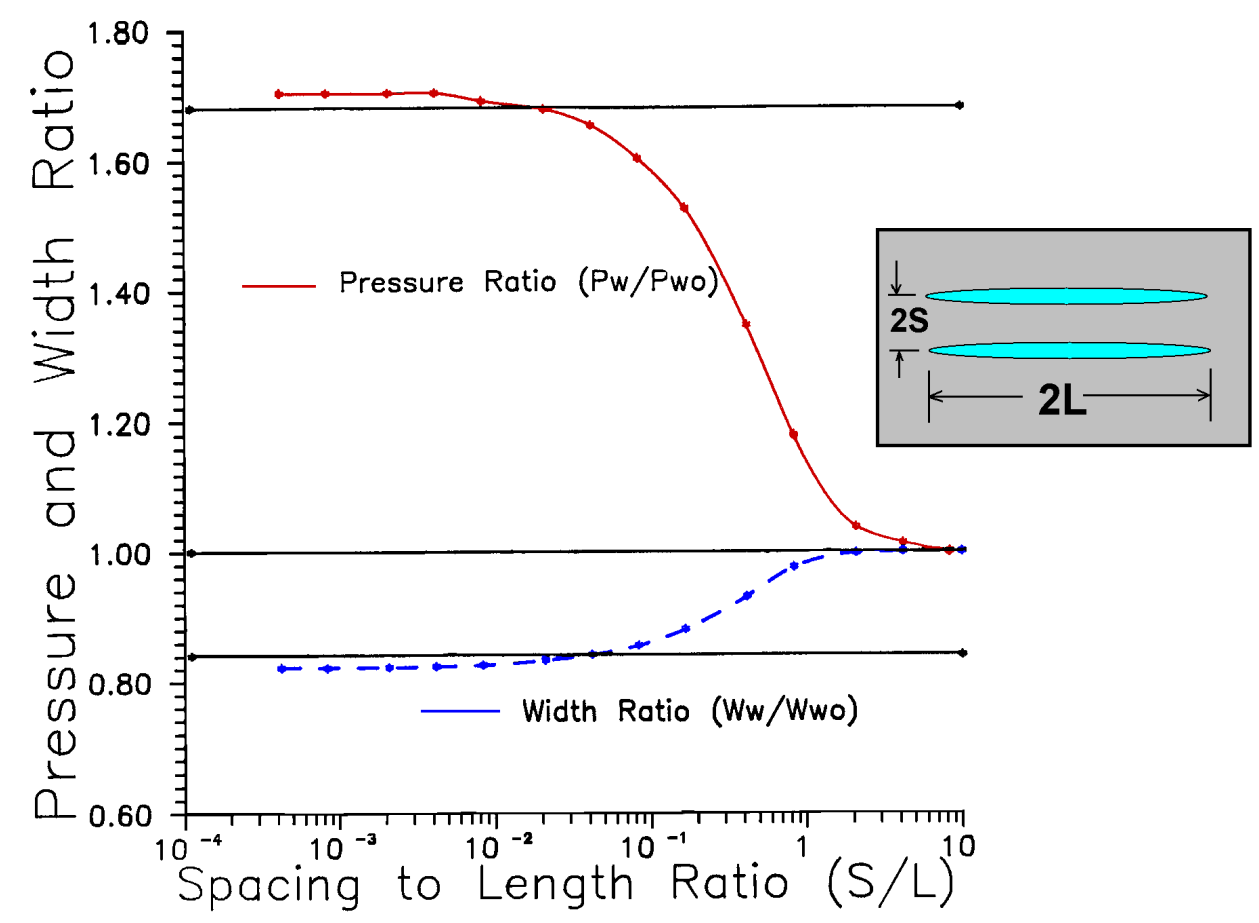

Figure 2 Pressure and width response for two parallel fractures (after Jeffrey et al., 1989). Pw and Ww are the net pressure and fracture width at the well for a two fracture case and Po and Wo are the net pressure and width at the well for a single non interacting fracture accepting one half the total injection rate

Germanovich and Astakhov (2004) analysed and discussed the case of more than two parallel fractures and point out that the overall width of such a system is not uniformly distributed among the fractures when they are interacting strongly with one another. The outside fractures are opened and the ones between these two outside fractures can be mostly closed. The pressure increase for multiple parallel fractures might then be about the same as for two parallel fractures.

\subsection{T-shaped fracture}

Because coal has a lower elastic modulus compared to typical roof and floor rocks, in a tectonic compressional stress environment, the horizontal stress in the coal seam is typically lower than the horizontal stress in the surrounding rock (Enever et al., 2000). Furthermore, in many seams the horizontal minimum stress in the seam is significantly less than the vertical stress in magnitude (Enever et al., 2000). Under such stress conditions, hydraulic fractures will start to grow as vertical fractures. The treating pressure will increase with fracture length when a vertical fracture contained in height to the seam thickness is being extended, which is a well known response for contained vertical fractures (Perkins and Kern, 1961). Other effects that are discussed in this paper add to the treating pressure and the pressure can quickly reach a value that is high enough to initiate horizontal fracture growth. The horizontal fractures usually form at the coalroof rock interface but have also been mapped in the seam (Figure 1(d)).

The interaction between the vertical and horizontal branches of such a fracture has been modelled in twodimensions (2D) and, as shown in Figure 3, results in local pinching of the fracture channel and elevation of the pressure (Figure 4) required to force fluid from the vertical to the horizontal branch (Zhang et al., 2007). The fluid in the 2D model is injected at the lower end of the vertical segment. At this point in the fracture development, the vertical fracture has grown to the interface and a horizontal fracture is being extended as indicated by the fracture opening distribution shown in the figure. The lengths of the lines drawn perpendicular to each fracture branch are proportional to the fracture opening at that point in the fracture. Note that the upper end of the vertical branch opens widely because of slip occurring along the horizontal 
interface. The reduced opening width of the horizontal fracture branch near the intersection point is also clearly seen in this figure and this reduced width is caused by the interaction between the vertical and horizontal branches.

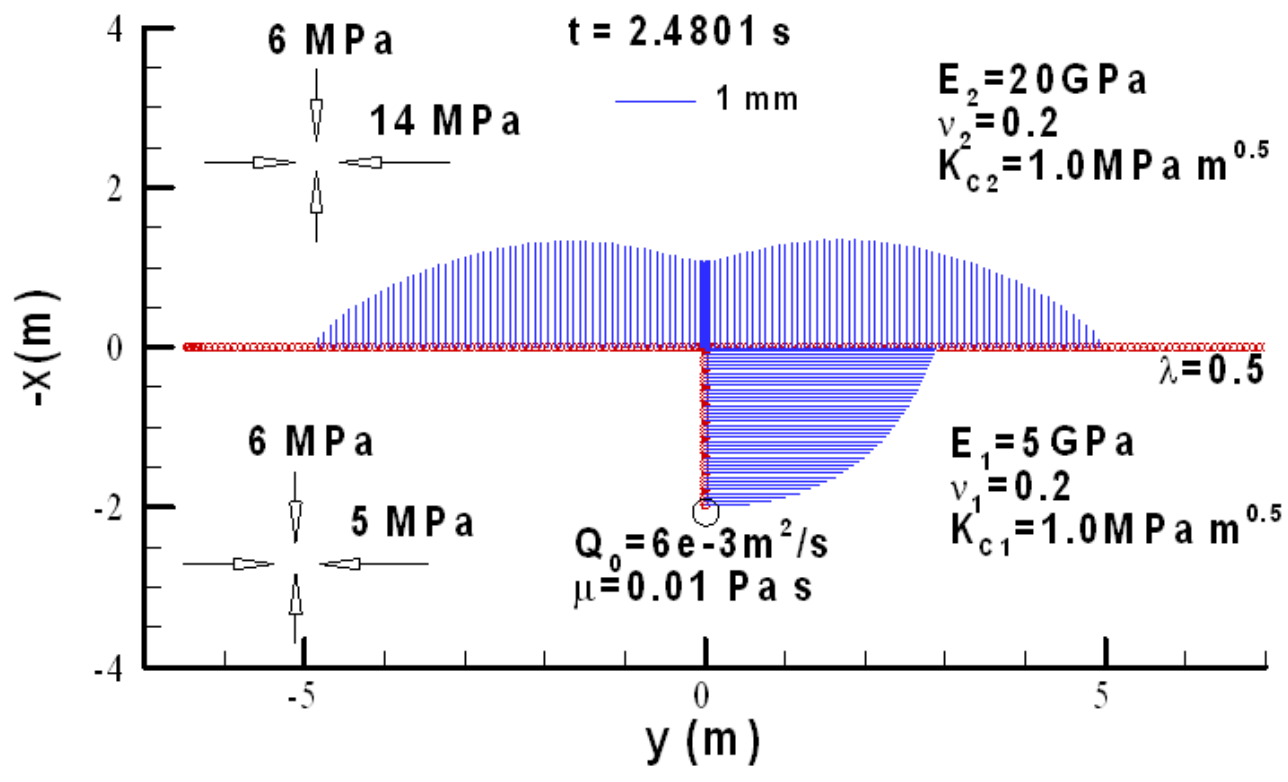

Figure 3 Example of opening of a T-shaped fracture by injected fluid. E is the rock Young's modulus, $v$ is the Poisson's ratio of the rock, $\mathbf{K}_{\mathbf{c}}$ is the fracture toughness of the rock, $\lambda$ is the coefficient of friction on the layer interface, $Q_{0}$ is the constant injection rate, and $\mu$ is the Newtonian dynamic viscosity of the fracturing fluid

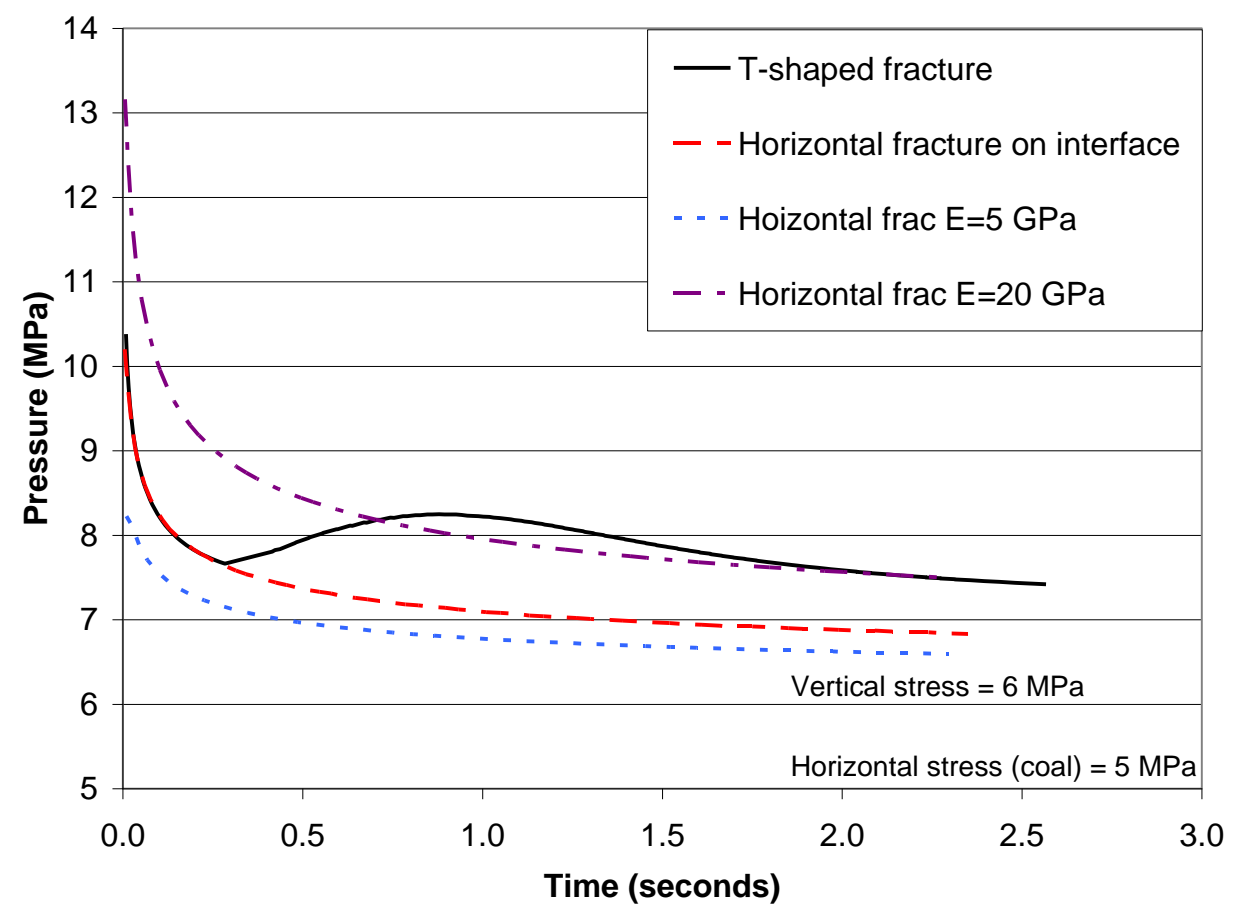

Figure 4 Pressure for a T-shaped fracture compared to other cases 
The pressure history of the T-shaped fracture is shown in Figure 4 along with several other cases for comparison. The highest pressure after initiation in the T-shaped geometry occurs as the vertical fracture intersects and eventually enters into the horizontal interface. Eventually, the pressure for all fracture cases shown in Figure 4 will asymptotically approach the magnitude of the far-field vertical stress, but for short and intermediated times the excess pressure (the pressure in excess of the far-field stress acting across the fracture plane) to extend the T-shaped fracture is up to twice that of a horizontal fracture growing on the interface between soft and stiffer rock layers. The horizontal fracture curves, provided for comparison, for $\mathrm{E}=5 \mathrm{GPa}$ and $\mathrm{E}=20 \mathrm{GPa}$ are for growth of a fracture with a horizontal orientation in a homogeneous rock with those properties. The curve corresponding to fracture growth along the interface without a vertical branch coincides with the $\mathrm{T}$-shaped curve during early times. This is a result of the combination of parameters used for this case and would not occur for all layer, interface and fracture properties.

\subsubsection{Elastic layer effect}

When a hydraulic fracture grows parallel to the bounding layers and in a layer of lower modulus that is bounded by layers of higher modulus, the effective modulus that governs the width development in the fracture depends on the size of the fracture relative to the thickness of the soft layer (Jeffrey et al., 1989). Initially the effective modulus is equal to the soft layer modulus, but as the fracture becomes larger it feels the modulus of the stiffer layers and eventually, for a large enough fracture, the effective modulus is equal to the modulus of the bounding layers. Figure 5 shows results of a numerical calculation illustrating this change in effective modulus with fracture size. The pressure in a hydraulic fracture is increased, the width is narrowed and the growth rate is increased as the apparent modulus increases, if other parameters controlling fracture growth are held constant.

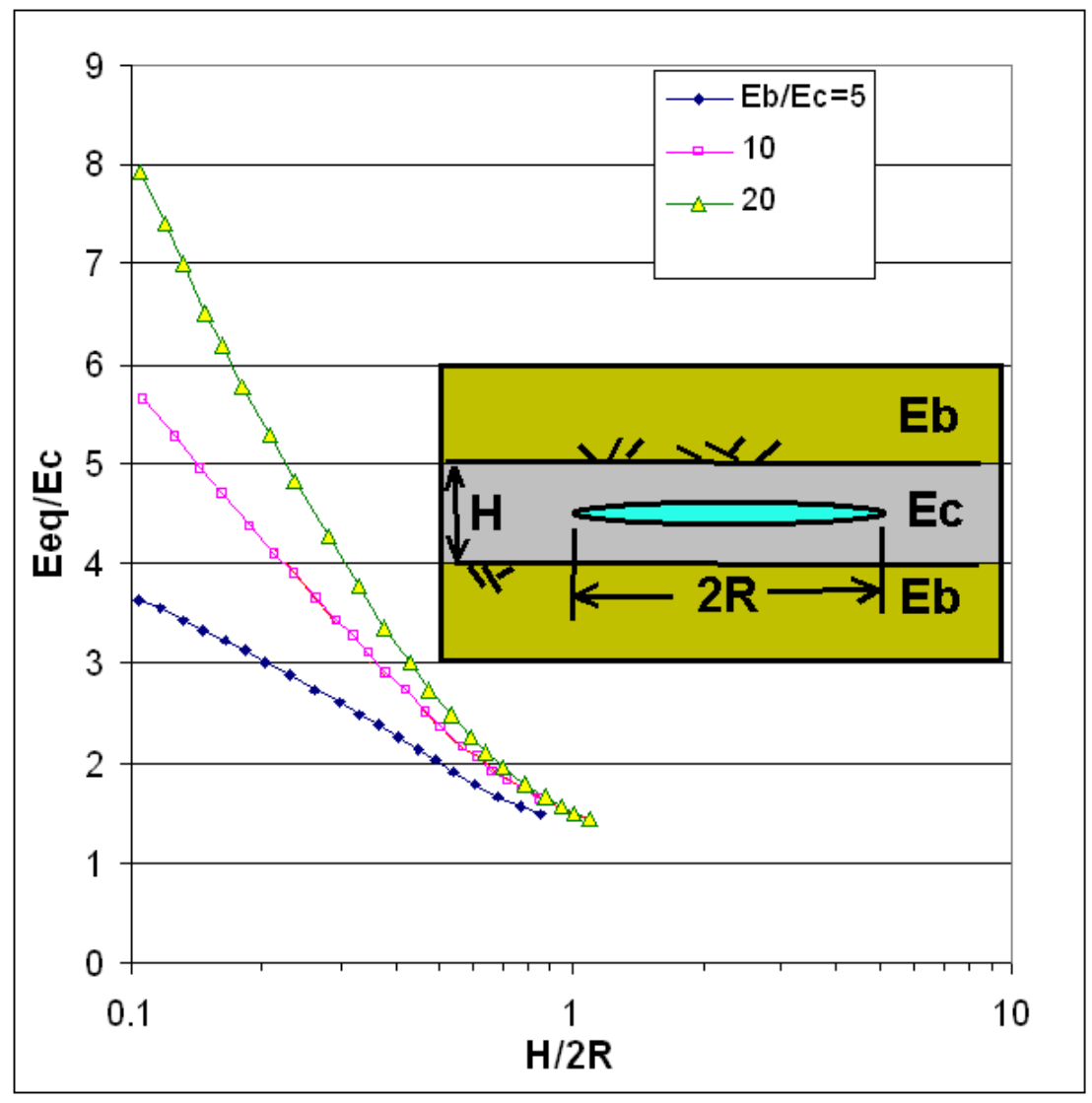

Figure 5 The equivalent modulus for three different modulus contrasts in a three layer system (after Jeffrey et al., 1989) 


\subsection{Poroelastic backpressure}

The rock layers above and below the coal seam are usually of much lower permeability than the seam. As a hydraulic fracture grows, fracturing fluid is lost into the surround material, increasing the pore pressure in it. This increase in pore pressure causes a slight swelling of the rock which induces a back stress on the hydraulic fracture, increasing the treating pressure. In an infinite reservoir rock, the induced back pressure will, in the limit of long time, cause a change in fracture width equal to $-\eta w_{0}$ where $w_{0}$ is the fracture width before any poroelastic effect develops (Detournay and Cheng, 1993). For the three layer case where only the central layer is permeable, the width change from the poroelastic effect is doubled to $-2 \eta w_{0}$.

The poroelastic parameter, $\eta$, ranges from 0 to 0.5 and is typically about 0.25 for reservoir rocks. The increase in fracturing pressure required to counter this tendency to decrease the fracture width is then also twice the corresponding increase predicted for a fracture growing in an infinite homogeneous poroelastic reservoir, assuming in both cases that the pressure increase is sufficient to counter all of the poroelasticinduced fracture width reduction (Detournay and Cheng, 1993). For a PKN-type fracture in a three metres thick coal seam, the pressure to compensate for a width reduction of $-2 \eta w_{0}$ would typically be in the range of $1.0 \mathrm{MPa}$.

\subsection{Non-linear leakoff}

The increase in pore pressure around the hydraulic fracture will reduce the effective normal stress acting across the natural fractures and cleat in the coal. Coal permeability is sensitive to the effective stress it is subject to, which is a response typical of all naturally fractured rocks (Wold and Jeffrey, 1999). Thus, as fluid is lost from the hydraulic fracture into the coal, the pore pressure increase that results also increases the permeability around the hydraulic fracture, leading to increased leakoff. Loss of fracturing fluid to leakoff has a strong effect on slowing fracture growth and limiting ultimate size. Jeffrey and Settari (1998) used a fracture model that included pressure dependent, non-linear leakoff to match growth data from an instrumented field hydraulic fracturing experiment in coal.

\subsection{Shear mobilisation}

As discussed immediately above, the natural fractures in coal impart a pressure sensitive permeability and leakoff behaviour to it. The increased pore pressure around the fracture reduces the normal effective stress acting across natural fractures. If these fractures are carrying some shear stress, they may then slip in shear. The hot dry rock geothermal industry pioneered stimulation by mobilising shear on natural fractures (Pine and Bachelor, 1984) and shear stimulation is gaining popularity in tight gas and shale gas reservoirs (Mayerhofer et al., 1997). The shear strength of a frictional joint or natural fracture is given by Equation 1, using the Mohr-Coulomb strength criterion,

$$
\tau=c+\left(\sigma_{n}^{T}-p\right) \tan (\varphi)
$$

where $\tau$ is the shear strength, $\mathrm{c}$ is the cohesive strength of the fracture, $\sigma^{T}{ }_{n}$ is the total normal stress acting across the fracture, $\mathrm{p}$ is the pore pressure in the fracture, and $\varphi$ is the friction angle of the fracture. $\left(\sigma^{T}{ }_{n}-p\right)$ is then the effective normal stress acting across the fracture. Shear movement on a rough fracture can result in shear dilation of the fracture as rough surfaces ride up over one another. Such shear dilation will increase the permeability of the coal seam. Shearing also has potential to create fines since some of the asperities on the fracture may fail and be ground up by the shearing. Some coal seam methane operators in Australia try to promote shearing by pumping water fracs at high rate (50 to $70 \mathrm{bpm}$ or 7 to $11 \mathrm{~m}^{3}$ per minute) and have reported good stimulation results with this approach. How much shearing is mobilised in the coal seam by these treatments is, however, not known.

The change in effective normal stress in the seam associated with the pore pressure increase will, by itself, cause some small opening of joints and fractures. This stress cycle may increase the permeability, without including the effect of shearing. However, laboratory core samples that are tested for permeability under confining stress tend to show a decrease in permeability with cycling of the confinement stress between tests (Enever and Hennig, 1997). 


\subsection{Offsets in the fracture channel}

Hydraulic fractures grow along and through natural fractures and joints in the coal. The hydraulic fractures can extend for $100 \mathrm{~m}$ or more in length and, in doing so, may connect shorter natural fractures together and cross other natural fractures and shear zones. Mined hydraulic fractures often contain offsets along their length and height where they have crossed a pre-existing fracture, joint, or shear zone. For example, in Figure 1(c), the fracture was offset at the mid-seam shear zone (MSSZ) and in Figure 1(a) the fracture has an offset near its lower left extent and contained other offsets that do not show at the scale of this drawing. Figure 6 is a photo taken looking up at the roof rock showing the trace of the fracture shown in Figure 1(a). The offset in this photo may have extended into the coal but that part of the coal was mined before mapping.

Offsets in the fracture path present a local restriction to fracture opening, which results in a pressure loss as the fracturing fluid flows through the offset. In addition, the reduced hydraulic fracture width through the offset can result in proppant bridging. The effect of such offsets on pressure and fracture growth is analysed next using a 2D hydraulic fracture model.

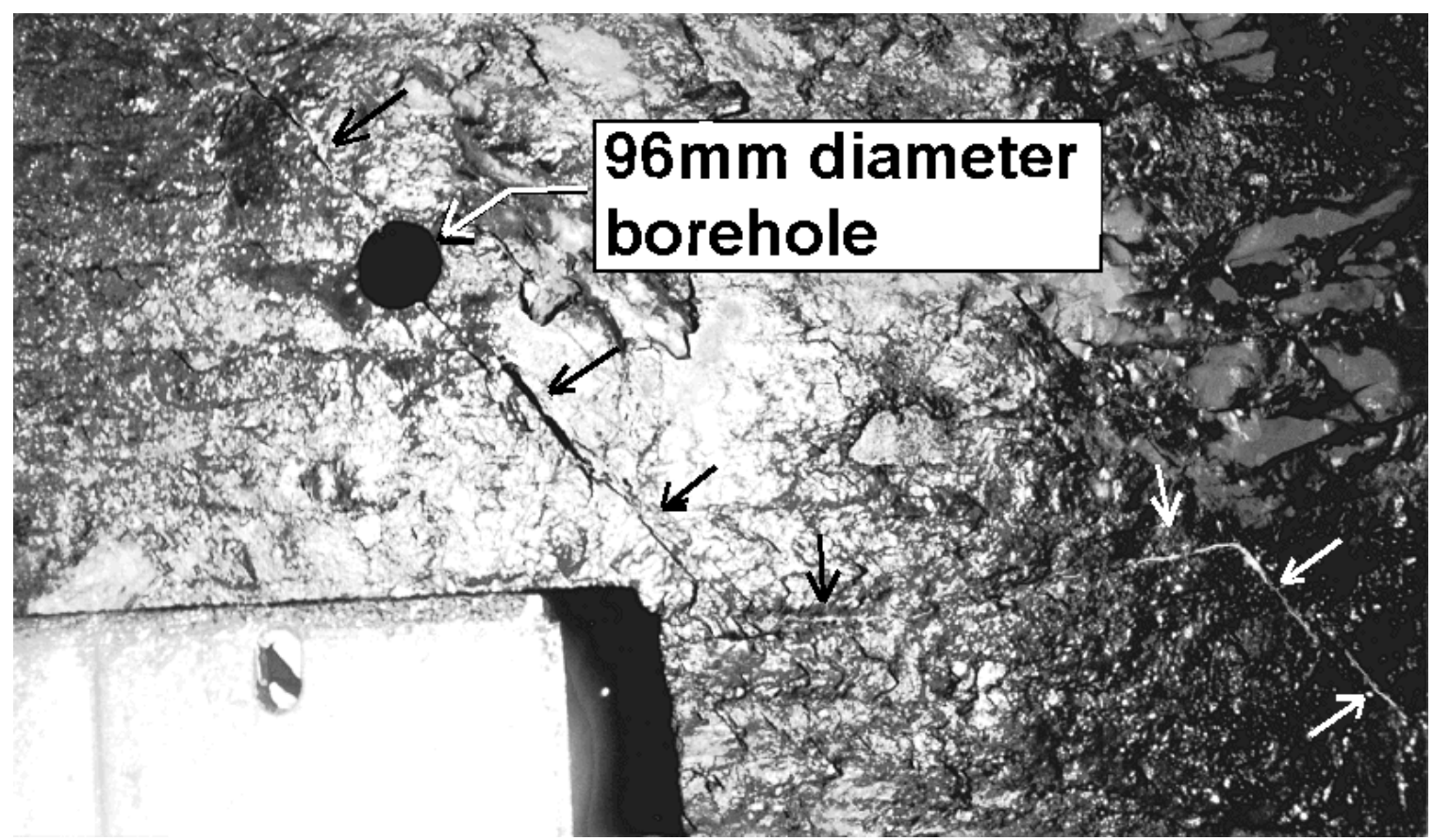

Figure 6 Photo of roof showing borehole and propped hydraulic fracture with $60^{\circ}$ offset extending from it - arrows indicate fracture trace

An idealised fracture with offsets pre-defined along its length is used here to study the effect such offsets have on fracture pressure and growth. The geometry analysed is shown in Figure 7 and consists of a fracture with several offsets, all of the same size and with the same offset orientation. The offset fracture is opened using a uniform pressure throughout. A uniform pressure loading corresponds to injection of a zero viscosity fluid and for such loading, only the fracture toughness of the rock limits fracture growth. The fracture growth is therefore said to be dominated by toughness (Detournay, 2004). As can be seen in Figure 7, the offset portions of the fracture are restricted in width, and this width or opening restriction is more extreme for the higher angle offsets. 


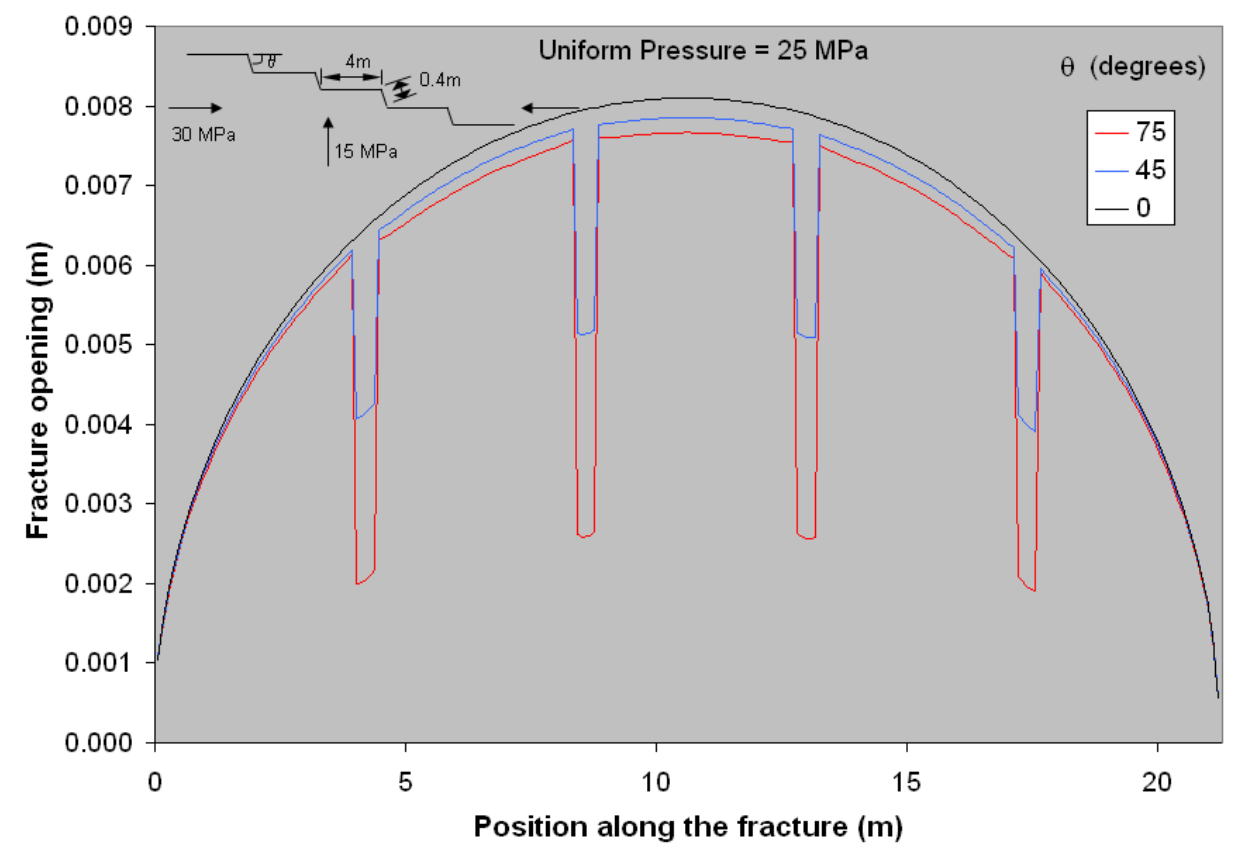

Figure 7 Fracture opening for three angles of the offsets along the fracture. Uniform pressure case with no viscous flow occurring
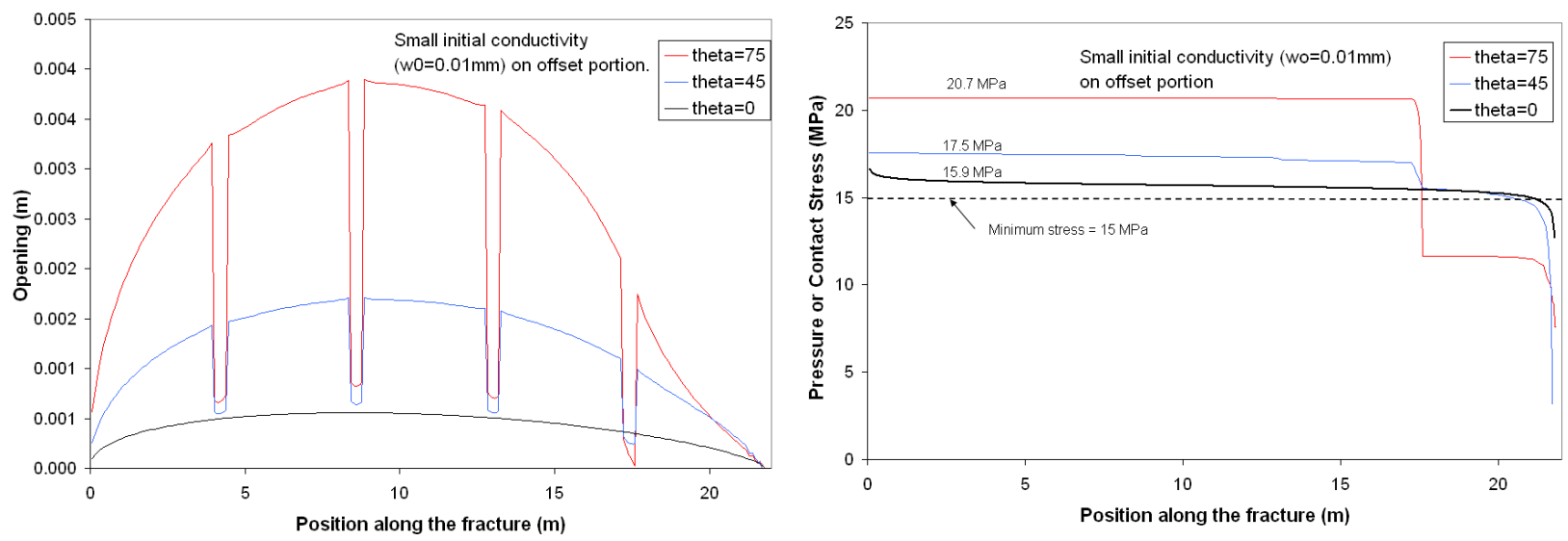

Figure 8 Fracture opening (left) and pressure (right) in the fracture with offsets for a case where water is being injected into the left end of the fracture at $24 \mathrm{~L} / \mathrm{min} / \mathrm{m}$ of fracture thickness in the out of the paper direction

When a viscous fluid is injected into a hydraulic fracture, the flow of the fluid in the fracture results in a pressure gradient along the fracture, which is a reflection of viscous dissipation of energy. Under many conditions, the energy dissipated by viscous fluid flow is much larger than the energy dissipated in overcoming the fracture toughness of the rock and, in such cases, the hydraulic fracture growth is said to be viscosity dominated (Detournay, 2004). Normally, the calculations for viscous dissipation assume a uniform resistance to fluid flow exists along the length of the fracture and, because of the narrowing of the fracture width near the tip, the highest pressure gradients and associated dissipation occurs there.

Figure 8 shows the opening and pressure along the fracture with offsets in its path for the case where water is injected at the left end at a rate of $24 \mathrm{~L} / \mathrm{min} / \mathrm{m}$ of fracture height or thickness (in this case the height is the dimension out of the plane of the page). The rock modulus is $50 \mathrm{GPa}$ and the Poisson's ratio is 0.22 for both the uniform pressure case and the injection case. The cases shown in Figure 8 are for a time when the fracture fluid has filled the entire stepped fracture. Injection at the left tip is not a physically realistic 
condition, but is a limitation of the current model. However, the pressure is only increased slightly because of the reduced fracture width at the left tip, as can be seen from the result of the straight fracture in Figure 8, where a small increase in pressure is seen at the left end of that pressure curve. Furthermore, this increase only occurs near the left tip. For the stepped cases, most of the pressure drop occurs as the fluid crosses the last step since at the time shown the other steps have been opened more widely by the pressure in the fracture, although these offset locations might still be sites for proppant bridging. Excess pressures values, $\mathrm{P}_{\mathrm{ex}}$, have been extracted from the data and are given in Table 1 for different angles of steps. The last column of Table 1 gives the ratio of the excess pressure to the excess pressure for a straight fracture, $\mathrm{P}_{\text {exo }}$.

Table 1 Excess pressure with step angle for the $22 \mathrm{~m}$ long fracture with steps

\begin{tabular}{ccc}
\hline $\begin{array}{c}\text { Step Angle } \\
\text { (degrees) }\end{array}$ & $\begin{array}{c}\mathrm{P}_{\mathrm{ex}} \\
(\mathrm{MPa})\end{array}$ & $\mathrm{P}_{\mathrm{ex}} / \mathrm{P}_{\mathrm{exo}}$ \\
\hline 0 & 0.9 & 1.0 \\
45 & 2.5 & 2.8 \\
75 & 5.7 & 6.3 \\
\hline
\end{tabular}

These results show that the increase in excess pressure produced as fluid flows along a hydraulic fracture with offsets can be significant and this mechanism alone can easily lead to treating pressures that would be considered abnormally high. The larger opening of the fracture that occurs for the offset cases (because of higher pressures) means that more of the injected fluid is stored in the fracture and this, in turn, slows fracture growth. Warpinski (1983) measured high fluid friction factors in an instrumented fracture experiment in tuff and attributed it to surface roughness, waviness, and offsets in the fracture channel.

\section{Discussion and conclusions}

Many of the potential causes for higher treating pressure and slower fracture growth in coal that have been described previously, are expected to act in combination during a treatment. Elevations in treating pressure, such as would be expected from propagation of a fracture with offsets along its length will contribute to a high enough pressure to form a T-shaped fracture. Offsets in the fracture plane have been mapped in horizontal and vertical branches of T-shaped fractures. The T-shaped fracture will, in turn, grow with an increasing equivalent modulus effect. Higher treating pressures in general will increase the pressure sensitive leakoff process, resulting in less efficient fractures that grow less rapidly and extend to a shorter final length.

The main factors that contribute to high treating pressure and shorter than expected fracture length are high viscous friction in the fracture channel, which can be attributed to pumping through parallel or branched fractures and through offsets, and the change of fracture geometry that occurs when a T-shaped or similar fracture forms. High leakoff rates that are pressure dependent are expected to be a common feature of fracture treatments in a naturally fractured material such as coal. A coal-specific fracture design model should include, as a minimum, these processes. Such a model could then be calibrated with field data and used to optimise the fracture treatment process with some confidence that the geometry predicted by the model is, at least approximately, similar to the fracture geometry produced.

\section{Acknowledgements}

The authors thank CSIRO for permission to publish this paper.

\section{References}

Detournay, E. (2004) Propagation regime of fluid-driven fractures in impermeable rocks, International Journal of Geomechanics, 4, pp. 35-45.

Detournay, E. and Cheng, A.H-D. (1993) Fundamentals of poroelasticity, Chapter 5 in Comprehensive Rock Engineering: Principles, Practice, and Projects. Vol. II, Analysis and Design Methods, C. Fairhurst (editor), Pergamon Press, pp. 113-171.

Diamond, W.P. and Oyler, D.C. (1987) Effects of stimulation treatments on coalbeds and surrounding strata, USBM report RI 9083. 
Elder, C.H. (1977) Effects of hydraulic stimulation on coalbeds and associated strata, USBM report RI 8260.

Enever, J.R., Jeffrey, R.G. and Casey, D.A. (2000) The relationship between stress in coal and rock, presented at the Fourth North American Rock Mechanics Symposium - NARMS 2000, Seattle, 31 July-3 August, pp. $409-414$.

Enever, J.R. and Hennig, A. (1997) The relationship between permeability and effective stress for Australian coals and its implications with respect to coalbed methane exploration and reservoir modelling, presented at the International Coalbed Methane Symposium, Tuscaloosa, 12-16 May, pp. 13-22.

Germanovich, L.N. and Astakhov, D.K. (2004) Stress-dependent permeability and fluid flow through parallel joints, Journal of Geophysical Research., 109, B09203.

Jeffrey, R.G. and Boucher, C. (2004) Sand propped hydraulic fracture stimulation of horizontal in-seam gas drainage holes at Dartbrook Coal Mine, in proceedings of the COAL 2004 Symposium, University of Wollongong, 4-6 February.

Jeffrey, R.G. and Settari, A. (1998) An instrumented hydraulic fracture experiment in coal, SPE 39908, Proceedings of the 1998 SPE Rock Mt. Regional/Low Permeability Reservoirs Symposium and Exhibition, Denver, 5-8 April.

Jeffrey, R.G., Settari, A. and Smith, N.P. (1995) A comparison of hydraulic fracture field experiments, including mineback geometry data, with numerical fracture model simulations, paper SPE 30508 presented at the 1998 SPE Annual Technical Conference and Exhibition, Dallas, 22-25 October, pp. 591-606.

Jeffrey, R.G., Vlahovic, W., Doyle, R.P. and Wood, J.H. (1998) Propped fracture geometry of three hydraulic fractures in Sydney Basin coal seams, paper SPE 50061 presented at the 1998 SPE Asia Pacific Oil and Gas Conference and Exhibition, Perth, 12-14 October.

Jeffrey, R.G., Weber, C.R., Vlahovic, W. and Enever, J.R. (1994) Hydraulic fracturing experiments in the Great Northern Coal Seam, paper SPE 28779 presented at the 1994 SPE Asia Pacific Oil and Gas Conference, Melbourne, 7-10 November, pp. 361-371.

Jeffrey, R.G., Byrnes, R.P., Lynch, P.A. and Ling, D.J. (1992) An analysis of hydraulic fracture and mineback data for a treatment in the German Creek coal seam, paper SPE 24362 presented at the 1992 SPE Rocky Mt. Regional Meeting, Casper, 18-21 May, pp. 445-457.

Jeffrey, R.G., Hinkel, J.J., Nimerick, K.H. and McLennan, J. (1989) Hydraulic fracturing to enhance production of methane from coal seams, paper 8992 presented at the 1989 Coalbed Methane Symposium, Tuscaloosa, 17-20 April, pp. 385-394.

Kravits, S.J. (1993) Evaluation of hydraulically fractured in-mine horizontal wells as a completion approach for coalbed methane recovery independent of, and in conjunction with coal mining operations, REI Underground Exploration Draft Report.

Mayerhofer, M.J., Richardson, M.F., Walker, R.N., Meehan, D.N., Oehler, M.W. and Browning, R.R. (1997) Proppants? We Don't Need No Proppants, paper SPE 38611 presented at the 1997 SPE Annual Technical Conference and Exhibition, San Antonio, 5-8 October.

Perkins, T.K. and Kern, L.R. (1961) Widths of hydraulic fractures, Journal of Petroleum Technology, September, pp. 937-949.

Pine, R.J. and Batchelor, A.S. (1984) Downward migration of shearing in jointed rock during hydraulic injections, Internatinal Journal of Rock Mechanics Mining Science and Geomechanics Abstracts, 21(5), pp. $249-263$.

Steidl, P.F. (1991) Inspection of induced fractures intercepted by mining in the Warrior Basin, Alabama, paper 9162 in Proceedings of the 1991 Coalbed Methane Symposium, Tuscaloosa, 13-16 May.

Warpinski, N.R. (1983) Measurement of width and pressure in a propagating hydraulic fracture, paper SPE/DOE 11648, Proceedings of the SPE/DOE Symposium on Low Permeability, 14-16 March, Denver, pp. 409-420.

Wold, M.B. and Jeffrey, R.G. (1999) A comparison of coal seam directional permeability as measured in laboratory core tests and in well interference tests, paper SPE 55598 presented at the 1999 SPE Rocky Mt Regional Meeting, Gillette, 15-18 May.

Zhang, X., Jeffrey, R.G. and Thiercelin, M. (2007) Deflection and propagation of fluid-driven fractures at frictional bedding interfaces: A numerical investigation, Journal of Structural Geology, 29, pp. 396-410. 
